\title{
Exuberant mesothelial proliferation mimicking malignant mesothelioma in a patient with prolonged VP shunt: A case report
}

\author{
Mohamad Kanso ${ }^{1}$, Cleo Massad ${ }^{2}$, Nina Shabb ${ }^{2}$, Bilal Anouti ${ }^{1}$, Reem Akel ${ }^{1}$, Mohamad Haidar ${ }^{3}$, Arafat Tfayli*1 \\ ${ }^{1}$ Division of Hematology and Oncology, Department of Internal Medicine, American University of Beirut, Beirut, Lebanon \\ ${ }^{2}$ Department of Pathology, American University of Beirut, Beirut, Lebanon \\ ${ }^{3}$ Department of Diagnostic Radiology, American University of Beirut, Beirut, Lebanon
}

Received: September 7, 2016

DOI: $10.5430 /$ crim.v4n1p4
Accepted: October 17, 2016

Online Published: November 3, 2016

\begin{abstract}
Background: Ventriculo-peritoneal shunt (VP shunt) surgery is the most widely used procedure in the treatment of hydrocephalus. Common complications post-VP shunt insertion are infection, mechanical failure, as well as functional complications such as over or underdrainage. Rarely, abdominal complications can present remotely after the time of VP shunt insertion. We found no reports in the literature describing peritoneal exuberant mesothelial hyperplasia mimicking mesothelioma, clinically, radiologically, and pathologically in a setting of VP shunt.

Case: A 22-year-old female with a history of T cell lymphoma in 2002, suffered from CNS recurrence and increased intracranial pressure (ICP) in 2004 necessitating a VP shunt insertion. In 2015, she presented with abdominal pain. CT scan of the abdomen showed omental nodular lesions that were biopsied and read first by a private pathology center as atypical mesothelial proliferation favoring malignant mesothelioma. However, after reviewing the full medical history and evaluating additional surgical material from the patient, review of the pathology specimen at the American University of Beirut concluded that the final diagnosis is atypical mesothelial proliferation favoring exuberant mesothelial hyperplasia possibly as a reaction to the long-standing VP shunt.

Conclusion: It is often difficult for the pathologist to differentiate a malignant from a reactive mesothelial hyperplasia especially on biopsies or limited material due to sampling issues. Many features of reactive mesothelial hyperplasia can mimic malignant mesothelioma. This complication took place in the setting of a VP shunt.
\end{abstract}

Key Words: Mesothelial hyperplasia, Ventriculo-peritoneal shunt, Malignant mesothelioma

\section{INTRODUCTION}

Ventriculo-peritoneal shunt (VP shunt) surgery is the most widely used procedure in the treatment of hydrocephalus. ${ }^{[1]}$ VP shunts relieve increased intracranial pressure caused by excessive cerebrospinal fluid (CSF) by creating a conduit for CSF to flow from the cerebral ventricles to the peritoneum. ${ }^{[2-4]}$ These devices have their own complications. Common complications are infection, mechanical failure as well as functional complications such as over or underdrainage. ${ }^{[4]}$ In addition, VP shunts are associated with sev-

\footnotetext{
*Correspondence: Arafat Tfayli, MD; Email: at35@aub.edu.lb; Address: American University of Beirut Medical Center, Naef K. Basile Cancer Institute, Riad El Solh 1107 2020, Beirut, Lebanon.
} 
eral rare abdominal complications that can present remotely after the time of surgery. ${ }^{[1]}$ Such complications include intestinal volvulus, pseudocyst, and extrusion through the scrotum, umbilicus, vagina, or gastrointestinal tract. ${ }^{[1]}$ However, there are no reports in the literature describing peritoneal exuberant mesothelial hyperplasia mimicking mesothelioma, clinically, radiologically, and pathologically in a setting of VP shunt.

\section{Case presentation}

This is a case of a 22-year-old female with history of $\mathrm{T}$ cell lymphoma diagnosed in 2002, and treated with the appropriate chemotherapy. In 2004, she had CNS recurrence, for which she received intrathecal chemotherapy and craniospinal radiation. She then suffered from increased intracranial pressure and a VP shunt was inserted, which was still in place when she presented to medical attention in October 2015. At that time she had been complaining of 1 month history of post prandial abdominal pain. Liver function tests were performed and showed no evidence of hepatic dysfunction. CT scan of the abdomen and pelvis revealed marked ascites and omental nodular lesions. Omental biopsy was done by diagnostic laparoscopy and was read by the Pathology Department at AUBMC. The patient was managed conservatively and showed improvement of her condition. No surgery was performed.
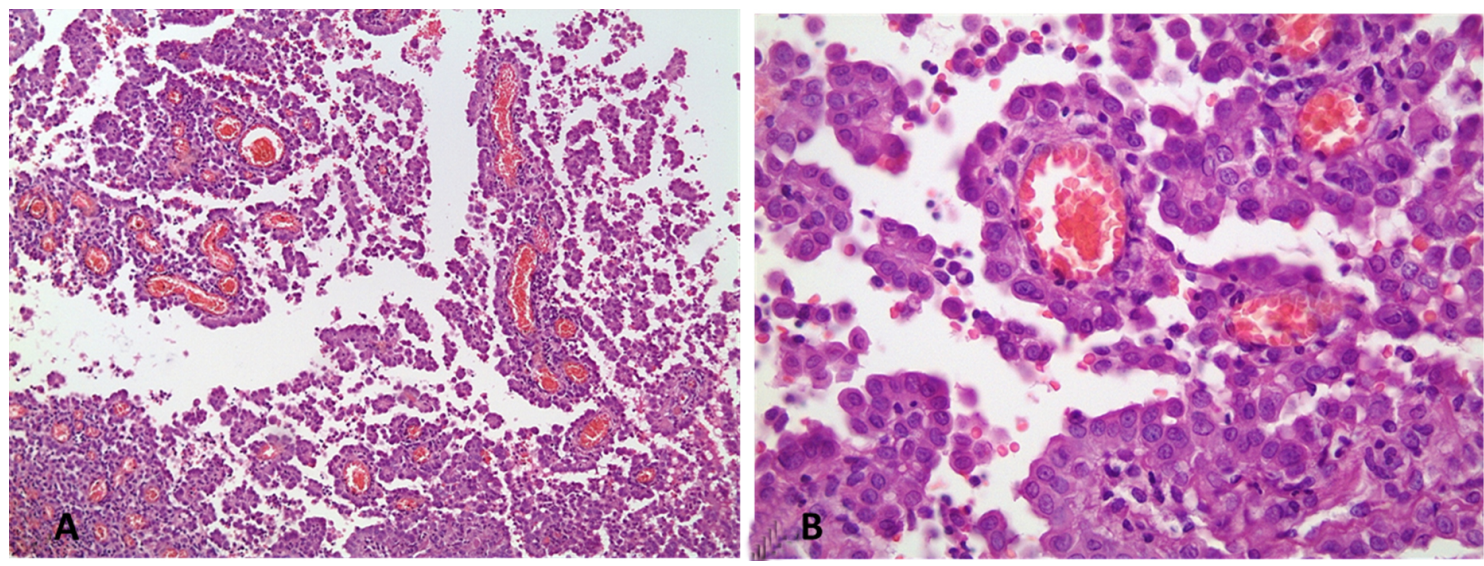

Figure 1. A. Exuberant papillary proliferation of relatively bland mesothelial cells (hematoxylin-eosin, original magnification $\times 100$ ); B. Exuberant papillary proliferation of relatively bland mesothelial cells (hematoxylin-eosin, original magnification $\times 400$ )

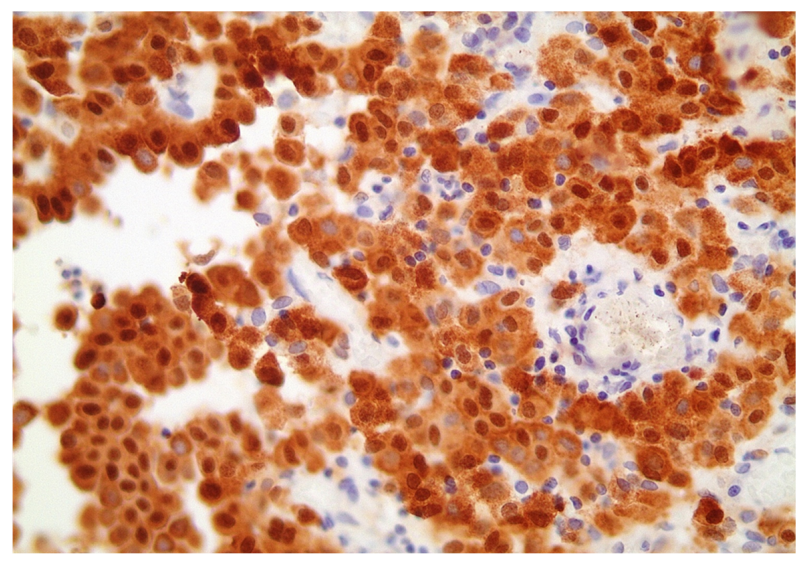

Figure 2. Calretinin staining mesothelial cells $(\times 400)$

Until now, patient continues to do well with minimal abdominal symptomatology and is being followed up regularly. She denies the recurrence of the abdominal pain and is doing well. She has not received active treatment regarding her described condition and no imaging studies were repeated due to her clinical stability. Moreover, the VP shunt is still in place.

\section{Pathology findings}

Originally, only one block was received from the private pathology center for consultation/review along with a corresponding pathology report read as malignant mesothelioma.

H\&E slides showed an exuberant proliferation of mesothelial cells with papillae composed of fibrovascular cores lined by many (more than 20) layers of monotonous mildly atypical mesothelial cells (see Figure 1). The mesothelial cells showed mild nuclear enlargement with occasionally enlarged nucleoli. There was no significant pleomorphism. Mitotic figures and necrosis were absent. There was no underlying stroma to determine the presence or absence of stromal invasion. The lesional cells were diffusely positive with EMA, CK5/6, calretinin (see Figure 2) and WT1. The differential diagnosis included malignant mesothelioma versus a reactive mesothelial proliferation. The slide was shown in consultation to four other pathologists. All concluded that it was an atypical mesothelial proliferation favoring malignant 
mesothelioma.

In view of the major prognostic and therapeutic implications of a malignant mesothelioma in a 22-year-old girl, the Pathology Department at AUBMC requested full medical history and additional surgical material. The Pathology Department was informed that the patient had long-standing VP (for increased ICP) and additional five blocks were received for review. H\&E slides showed a mesothelial proliferation limited to the superficial mesothelial surface. The stroma was available for evaluation and no stromal invasion was noted (see Figure 3). Mesothelial cells were bland with no mitoses, atypical mitoses or necrosis. Additional immunohistochemical stains were performed and showed focal p53 and desmin positivity. Ki67 proliferation index was $10 \%$.

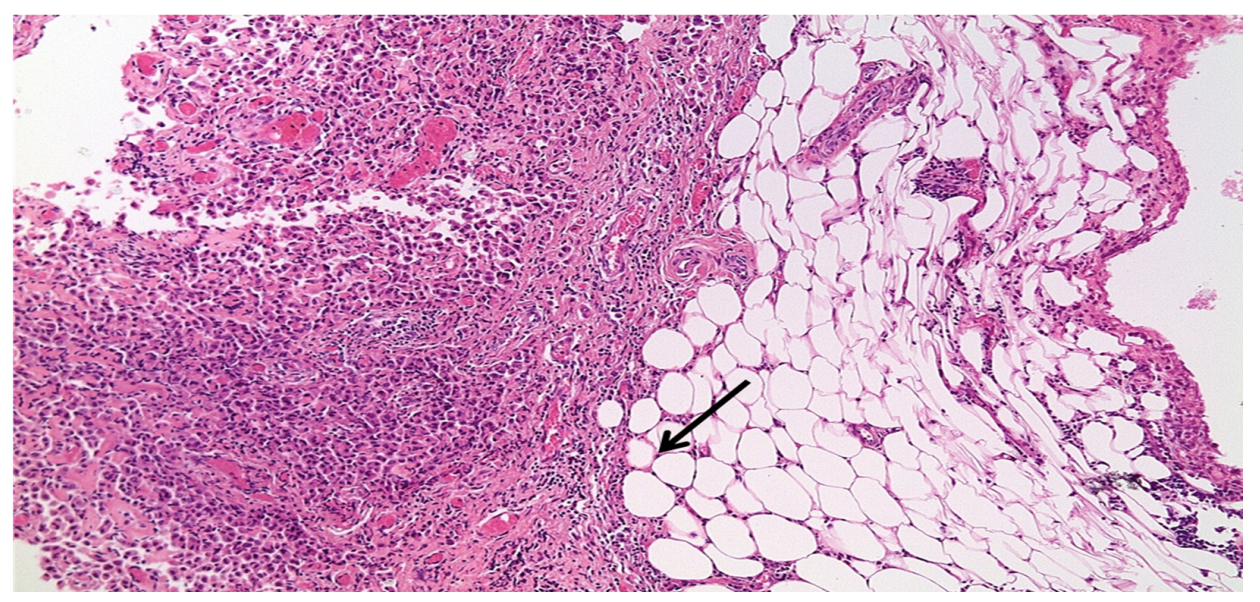

Figure 3. Arrow showing a proliferation of mesothelial cells limited to the surface without stromal invasion (hematoxylin-eosin, original magnification $\times 100$ )
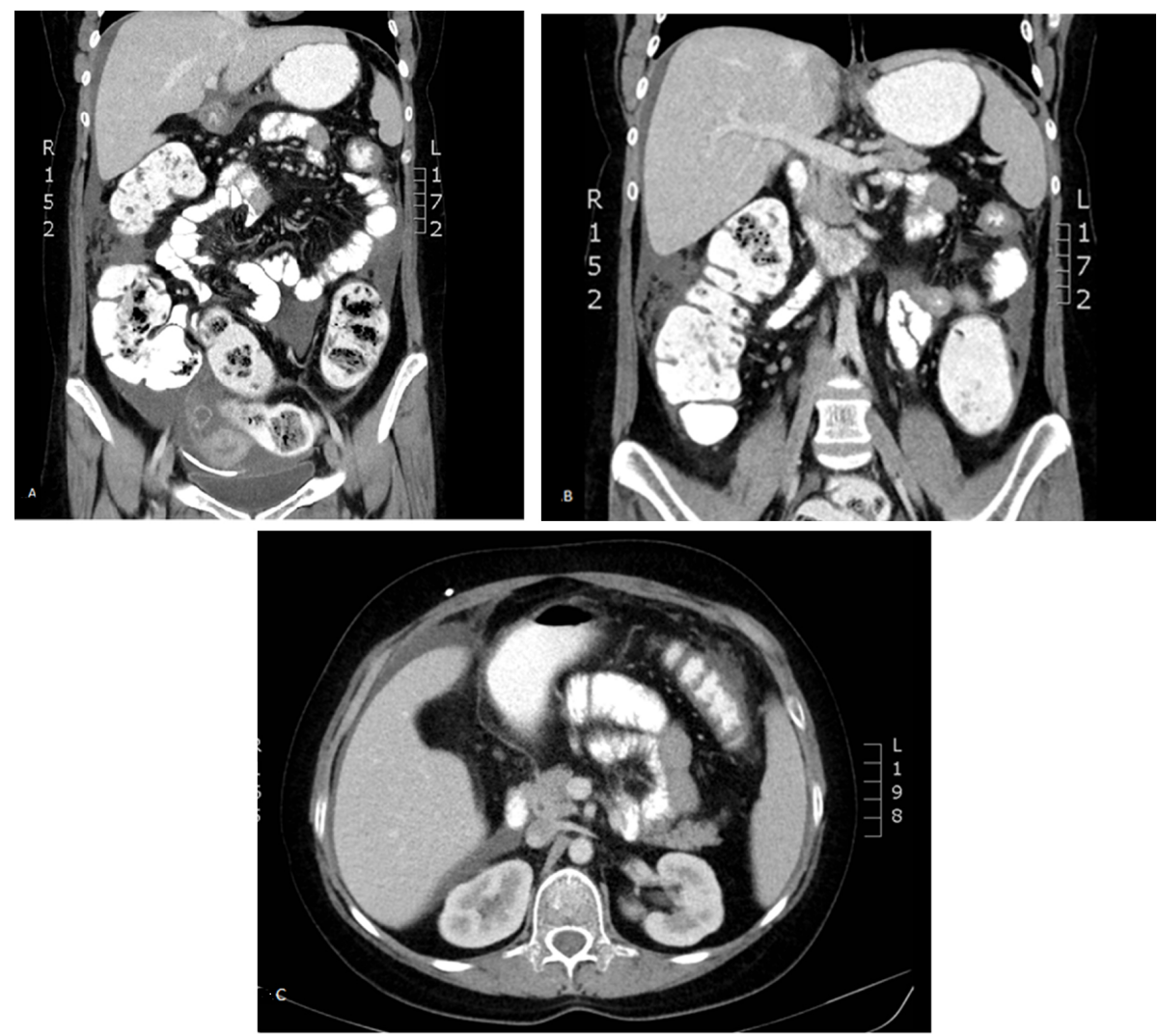

Figure 4. CT scan of the patient's abdomen and pelvis showing a right VP shunt in the pelvis (A), nodular lesions invloving the omental wall suspicious of omental masses (A, B, \& C), and marked abominal and pelvic ascites (C) 
In view of the history of long-standing VP shunt and the absence of stromal invasion, the final diagnosis was atypical mesothelial proliferation, favoring exuberant mesothelial hyperplasia possibly as a reaction to the long-standing VP shunt (see Figure 4).

\section{Discussion}

It is often difficult for the pathologist to differentiate a malignant from a reactive mesothelial hyperplasia especially on biopsies or limited material due to sampling issues. ${ }^{[5]}$ Many features of reactive mesothelial hyperplasia can mimic malignant mesothelioma such as the presence of multiple layers of cells and the presence of papillary excrescences with true fibrovascular cores. ${ }^{[5]}$ The presence of cytologic atypia and mitoses can also be misleading, however mesothelial cells are ill-reputed for showing greater degree of cytologic atypia in benign reactive conditions than in malignant ones. ${ }^{[5]}$ Nevertheless, the absence of stromal invasion remains the most reliable criterion in ruling out a malignant mesothelial proliferation. ${ }^{[5,6]}$
Certain immunohistochemical stains have been proposed to help distinguish benign from malignant mesothelial proliferations. However, these are not specific or sensitive enough to make a conclusive diagnosis. ${ }^{[5]}$ EMA and p53 (two proposed markers of malignancy) and Desmin (a proposed indicator of benign mesothelial cells) were not useful in our case since all three were at least focally positive.

The differential diagnosis of papillary mesothelial proliferations also includes well-differentiated papillary mesothelioma, a papillary tumor occurring in the peritoneum of young women. The papillae in this entity are lined by a single layer of bland flattened to cuboidal mesothelial cells. ${ }^{[7]}$ This diagnosis is ruled out in our case since more than 20 layers of cells were present around some of the fibrovascular cores. A diagnosis of mesothelioma in-situ can also be entertained, however there are currently no solid rules for differentiating it from reactive mesothelial hyperplasia on histology alone. ${ }^{[6]}$

\section{CONFLICTS OF INTEREST Disclosure}

The authors have declared no conflicts of interest.

\section{REFERENCES}

[1] Sathyanarayana S, Wylen EL, Baskaya MK, et al. Spontaneous bowel perforation after ventriculoperitoneal shunt surgery: case report and a review of 45 cases. Surgical Neurology. 2000; 54(5): 388-396. http://dx.doi.org/10.1016/S0090-3019(00) 00334-7

[2] Ames RH. Ventriculo-peritoneal shunts in the management of hydrocephalus. Journal of Neurosurgery. 1967; 27(6): 525. PMid:6065126 http://dx.doi.org/10.3171/jns.1967.27.6.0525

[3] Hoppe-Hirsch E, Laroussinie F, Brunet L, et al. Late outcome of the surgical treatment of hydrocephalus. Child's Nervous System. 1998; 14(3): 97-99. PMid:9579862 http://dx.doi.org/10.1007/s00 3810050186
[4] Nguyen TA, Cohen PR. Scalp necrosis overlying a ventriculoperitoneal shunt: a case report and literature review. Dermatology Online Journal. 2015; 21(10).

[5] Cagle PT, Churg A. Differential diagnosis of benign and malignant mesothelial proliferations on pleural biopsies. Arch Pathol Lab Med. 2005; 129(11): 1421-7. PMid:16253023

[6] Churg A, Galateau-Salle F. The separation of benign and malignant mesothelial proliferations. Arch Pathol Lab Med. 2012; 136(10): 1217-26. PMid:23020727 http://dx.doi.org/10.5858/arpa. 2012-0112-RA

[7] Travis WD, Harris C. Pathology and genetics of tumours of the lung, pleura, thymus and heart. 2004: Feance: IARC Press. 2004. 